كلمة التحرير

\title{
نداء من أجل العربية
}

\section{أحمد الريسولن*}

اللغة والدين هما المحددان الأساسيان لهوية أية أمة من الأمم وانتماءاتها على مر التاريخ. ويزداد هذان المحددان قوة

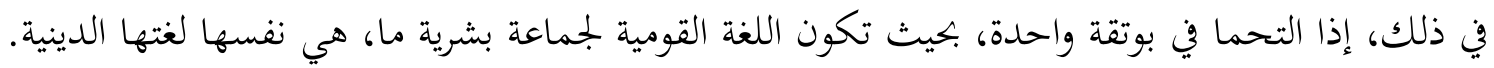

ورغم المحاولات الحديثة والحثيثة، لإعادة تشكيل الأمم والشعوب وانتماءاتا والانتماء إليها، على أسس جغرافية

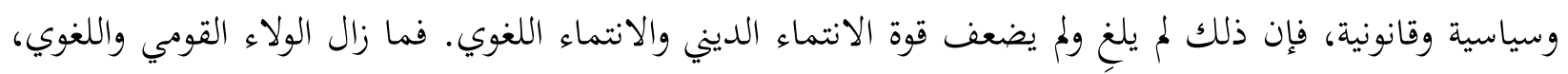

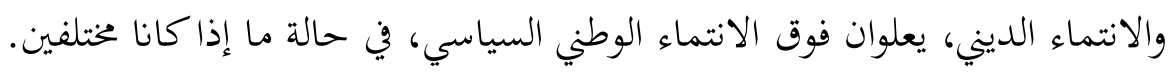

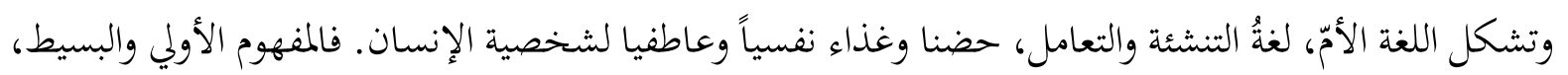

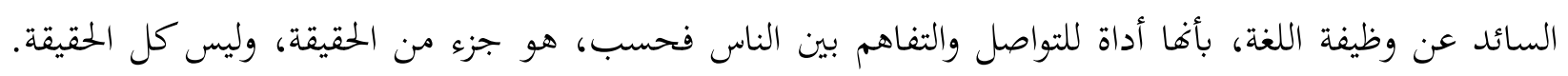

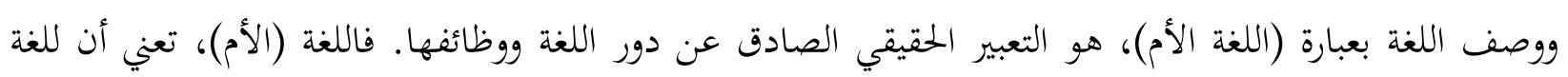

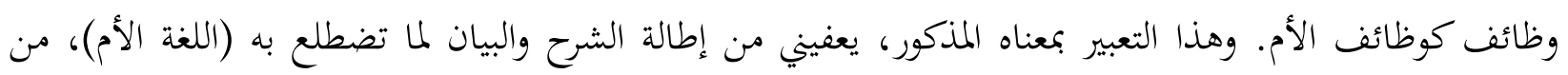

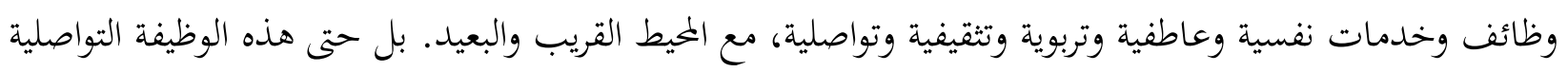

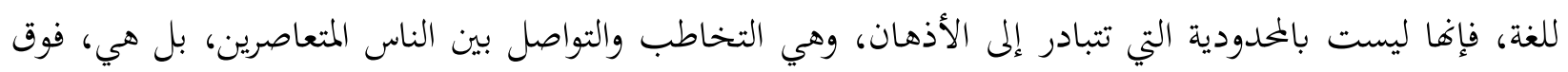

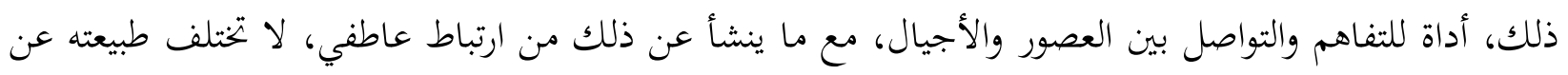
ارتباط الشخص بأقاربه وأصدقائه ومعاصريه.

ولحكمةٍ ما، أرادها الله تعالى، كانت المسألة اللغوية حاضرة منذ اللحظة الأولى لخلق الإنسان، فقد كان أول تعليم

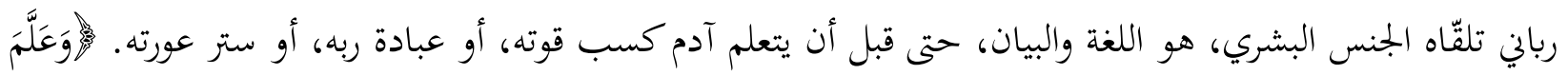

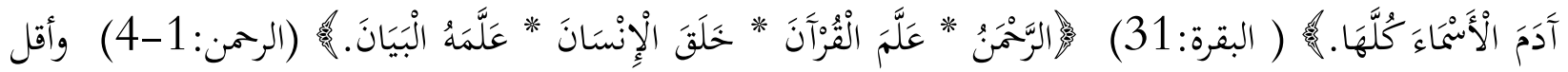
درس يستفاد من هذا، هو أن لِلُّة وظيفة أساسية وعاجلة في حياة الإنسان.

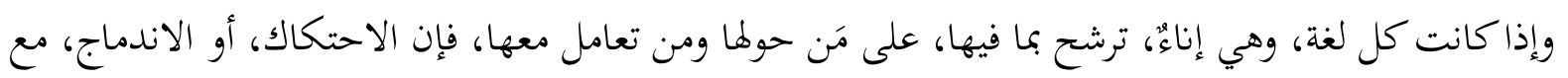

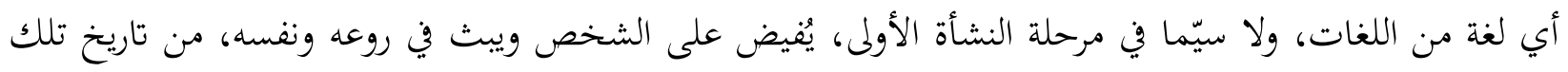
اللغة وأدجا وثقافتها وقيمها وذكرياتما.

raissouni@maktoob.com خ خبير في مجمع الفقه الإسلامي الدولي، وعضو هيئة تحرير بحلة إسلامية المعرفة، * 
فالانتماء اللغوي/الثقافي للأشخاص وللمجموعات البشرية، يتجاوز في تأثيره حتى الانتماء العرقي نفسه؛ ولذلك الك الكاء

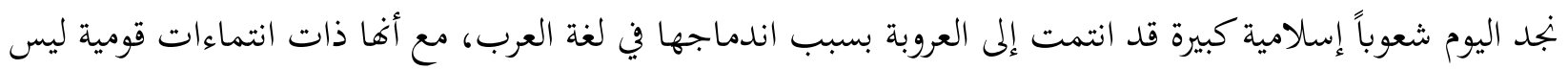

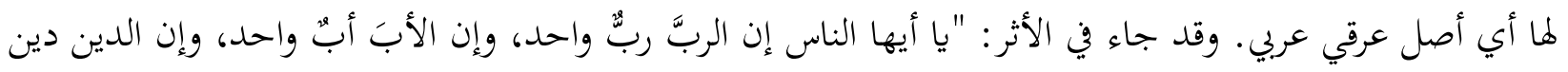

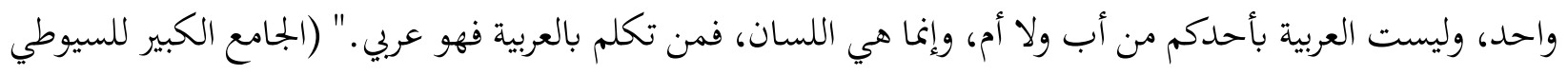

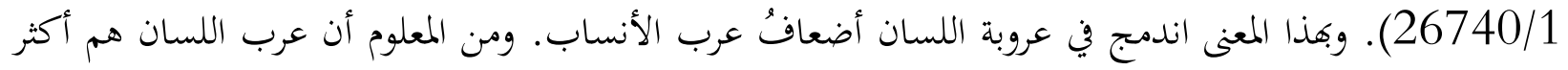

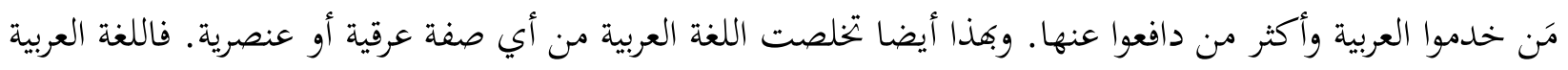

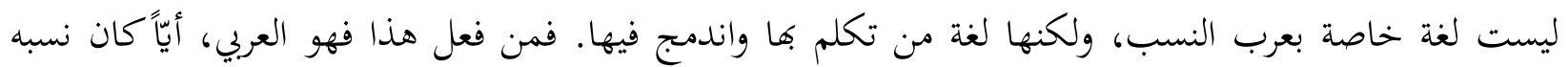
وسلالته.

كما أن (اللغة الأم) تشكل وسيلة لا بديل عنها، لأي إبداع، أدبي أو علمي، مستقل ومتميز. ودوهما لا تكون

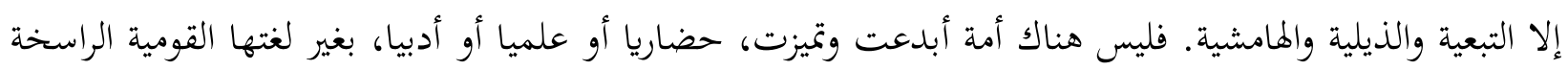

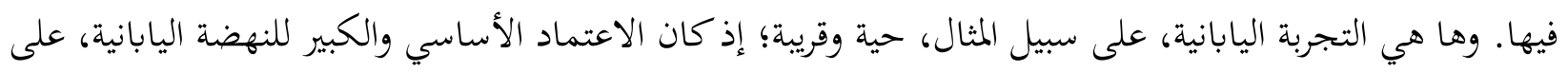

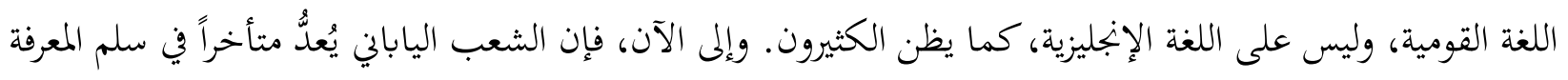

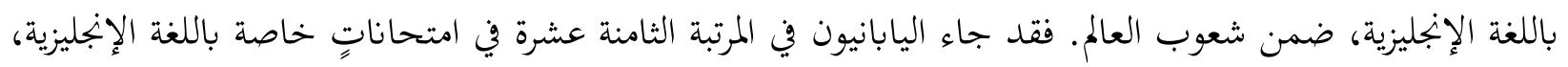

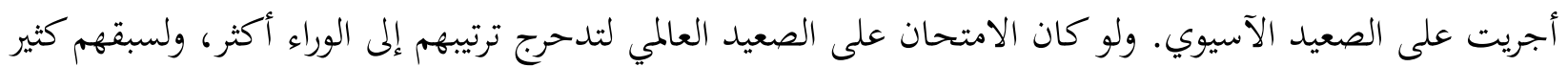
من العرب!

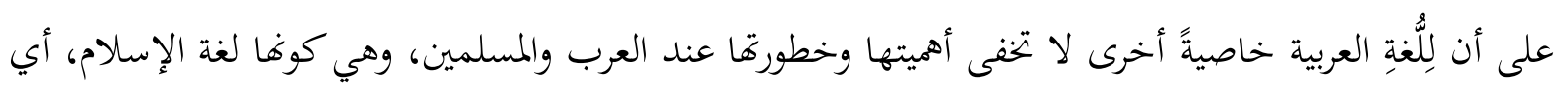

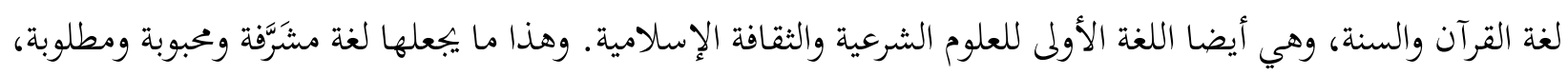
عند مئات الملايين من المسلمين من غير العرب. ولكن هذه الخصائص والوظائف الكبيرة والخطيرة، سواء التي تشترك فيها اللغة العربية مع غيرها من اللغات العالمية،

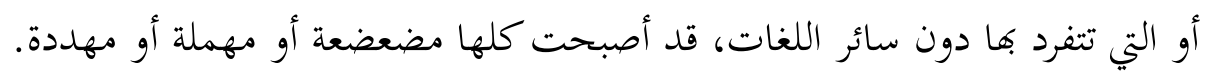

لقد أصبح الكثيرون من النخب العربية، ومن المسؤولين العرب، يجيدون ويمجدون اللغات الأجنبية، أكثر بكثير مما

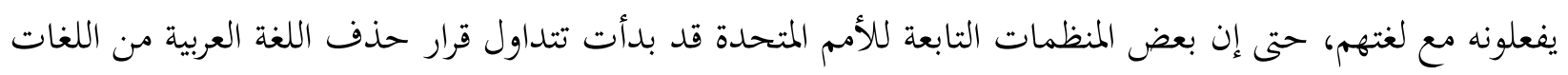

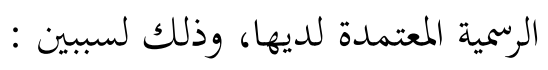

الأول: هو أن ممثلي الدول العربية أنفسهم لا يستعملون لغتهم العربية داخل هذه المنظمات، حرصا منهم على إظهار معرفتهم باللغة الأجنبية.

والثاني: هو أن الدول العربية غير ملتزمة بتعهداتها المالية والبشرية، في دعم متطلبات استعمال العربية في أجهزة 
على أن هذا التفريط الرسمي العربي في اللغة القومية الرسمية، على صعيد الأمم المتحدة، وعلى الصعيد الدولي بصفة

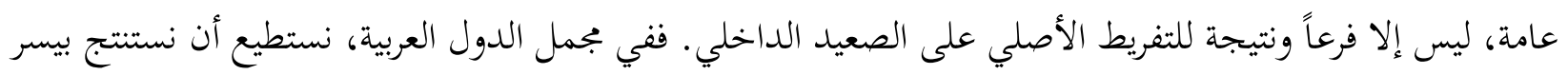
ووضوح، عدم وجود أي رغبة جديّة، ولا أي سياسة حقيقية، لتقوية اللغة العربية وتعزيز مكانتها الداخلية والخارجية. وفي كثير من هذه الدول لا يستطيع الملاحظ أن يستنتج أن اللغة العربية هي اللغة (الرسمية) للبلد! فاللغات الأجنبية تواصل اكتساحها واحتلالما لمواقع السيادة والريادة، على الخريطة العربية، في مجالات التعليم والإعلام، والإدارات والمعاملات الحكومية، والمرافق الاقتصادية والتجارية والخحداتية. وهي في ذلك معززة بجهود وخخططات ومؤسسات وتمويلات. وهكذا تستولي اللغة الإنجليزية على المشرق العربي، وتستولي اللغة الفرنسية على المغرب العربي. وبجانب الاكتساح اللغوي الأجنبي ومؤسساته التعليمية وغيرها، بدأ يستفحل استعمال العامية في الإعلام والتعليم كذلك، ففي الثانويات، ولا نتحدث عما دوها، وكذلك في الجامعات، وحتى في أقسام الدراسات العليا، يتزايد استعمال الطلبة والأساتذة لِلَهَجاقم العامية، أو لخليط بين الفصحى والعامية. وأما في الإعلام، وخاصة الإعلام المرئي منه ، فالأمر أسوأ وأفدح. ومن أمثلته القريبة: البرنامج الذي كان يقدمه صحفي عربي كبير وكاتب قومي شهير، على أكثر القنوات التلفازية العربية شهرة، وكان حريصا ألا يتحدث فيه إلا بعامية كاملة، كأنما يتحدث إلى أصدقائه وأقاربه في المدينة التي جاء منها! مع أن في ذلك خسارة إعلامية كبيرة للمتحدث وللقناة ذات الطابع العربي الدولي. وقد بدأنا نرى دعاة ومحاضرين مشاهير، يخاطبون في دروسهم ومحاضراتم جمهورا عربيا متنوع الأوطان واللهجات، ولكنهم، مع ذلك، يظلون غارقين في عاميتهم المحلية الخاصة، مما يجعل كثيرا من الناس ينصرفون عنهم، أو يصبرون

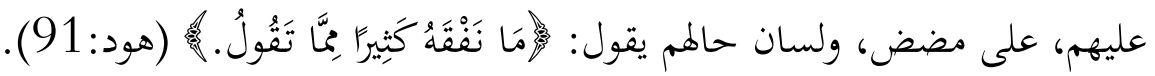
وفي هذا السياق أيضا انبعثت، بعد فشل قديم، دعوات متحمسة ومبادرات فعلية، لمحاولة ترسيم اللهجات العامية واتخاذها بدائل عن الفصحى. وهكذا ظهرت في المغرب العربي، على سبيل المثال، صحف وإذاعات وقنوات، مكتوبة وناطقة بالعامية. ولحسن الحظ، فإن أصحابها يشتكون من إعراض الجمهور عنهم واستهجانه لعملهم. ذلك أن عامة الناس، بمن فيهم الأميون وأشباه الأميين، يفضلون لغة فصيحة ميسرة، على العامية المغرقة في محليتها وخصوصيتها وقلة جدواها. فهم يريدون خطاباً يرتقي بهم لا خطاباً يهط من شأفم. وهناك خطر آخر يتهدد العربية والعروبة في عقر دارها، وفي بيت آبائها وأجدادها. ويتعلق، بصفة خاصة، بالدول والمجتمعات العربية، التي تحتضن وتستقبل الملايين من الوافدين والمقيمين غير العرب، تفوق أعدادهم أحيانا عدد السكان من أهل البلد. فهذا الوضع يشكل وينتج عملية تعجيم لغوي، عفوي وهادئ، لفذه المجتمعات؛ عملية التعجيم هذه تتمثل في استعمالات مشوهة وغريبة للتعبيرات والألفاظ العربية وغير العربية، هي آخذة في الزيادة والشيوع. كما تتمثل في الاختفاء الكامل أو شبه الكامل للتعامل باللغة العربية، بما فيها العامية المحلية، من عدد من المرافق الإدارية والاقتصادية والصحية والسياحية، وحلول اللغات الأجنبية محلها. 
يقع هذا في الوقت الذي تتيح هذه الحالة، حالةُ وجود ملايين المقيمين من غير العرب في المجتمعات العربية، فرصة

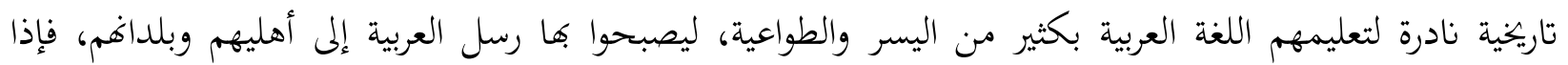

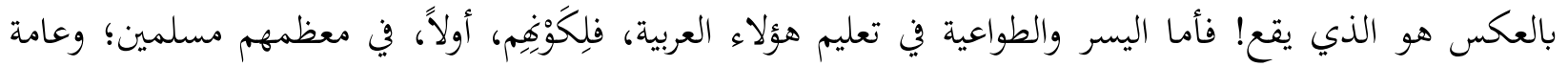

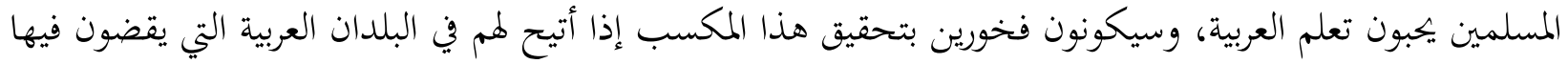

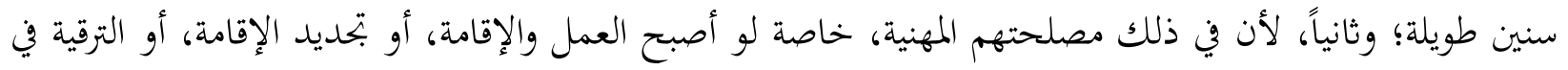

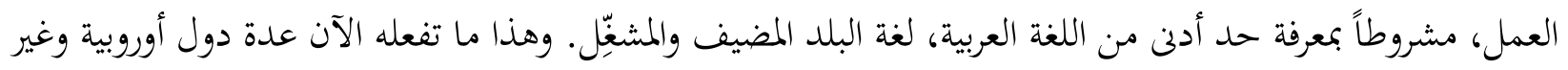
أوروبية.

على أن هناك فرصة أخرى لا يتم التجاوب معها واستثمارها، للحدمة اللغة العربية وتعزيز مكانتها العالمية، وهي

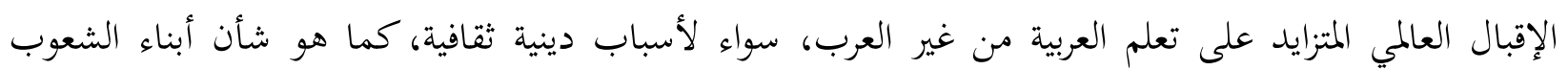

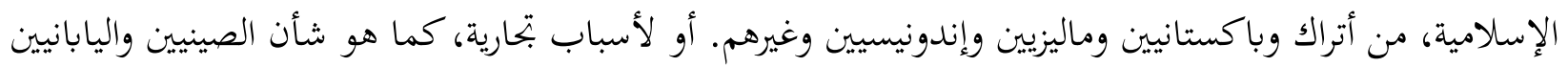

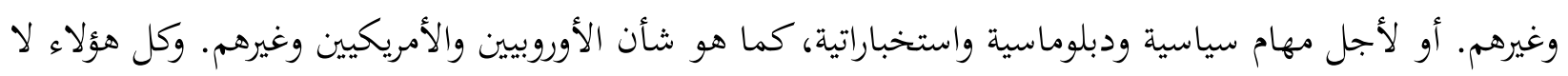

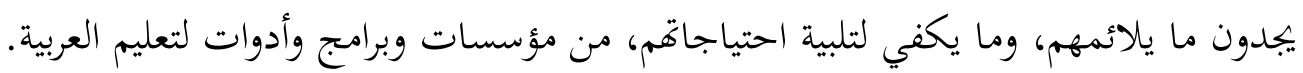
ولقد رأيت العشرات من الطلبة الآسيويين في الدراسات الإسلامية بالمغرب، حريصين كل الحرص على تحصيل

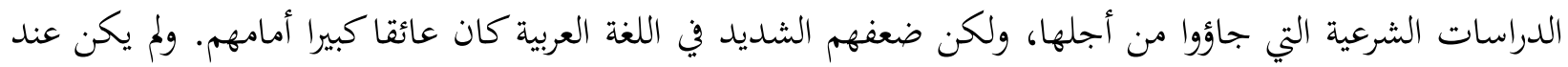

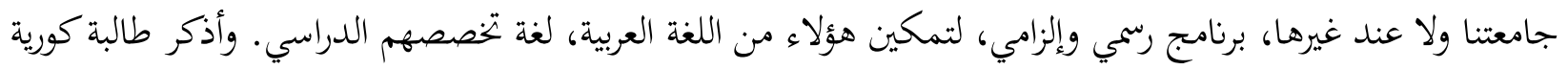

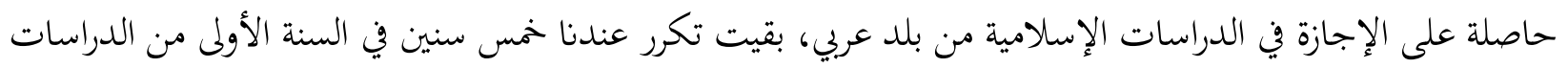

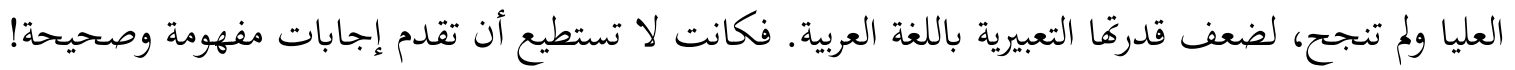
إن المسألة اللغوية عموماً، ومسألة اللغة العربية تحديداً، تستدعي وتستحق جهوداً أكبر بكثير مما تأخذه الآن. ولا أراني مبالغا إذا قلت إن قضية اللغة العربية تحتاج إلى صحوة وحركة، على غرار الحركة الإسلامية والصحوة الإسلامية.

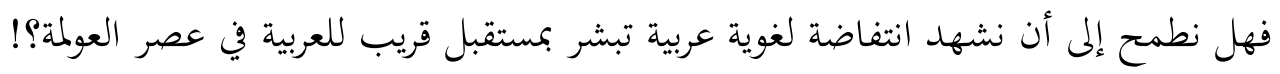
نحن نجد، والحمد لله، ردود فعل إيجابية، مقدرة ومشكورة، في الدفاع عن الإسلام وبي الإسلام، وعن القرآن

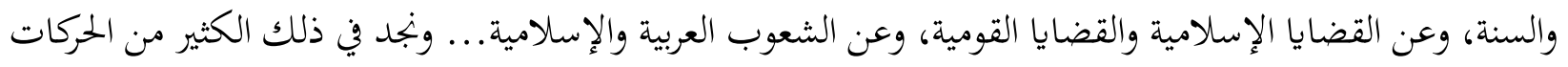

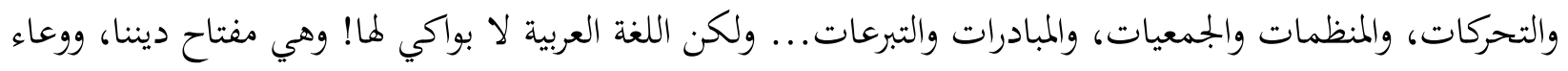

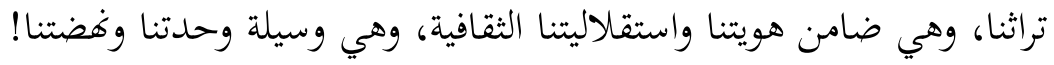

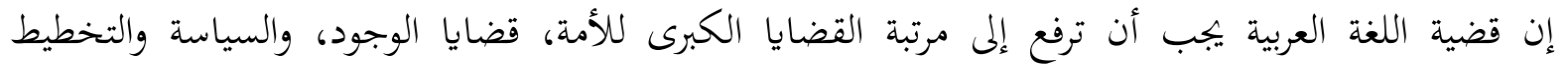

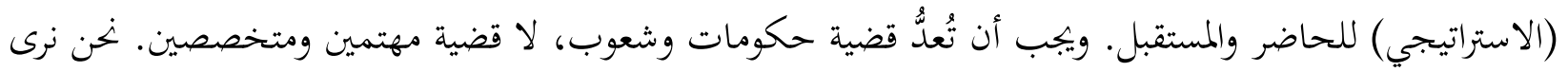

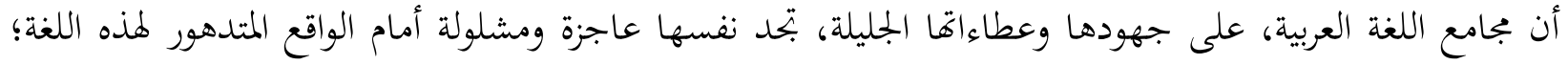
ذلك أها دون أنصار، ودون بتحاوب رسمي، ولا سند شعبي، ولا يكاد يعلم بقضيتها أحداء 
إن تحريك هذه القضية والانطلاق بها في مسارها ونخو أهدافها، يحتاج إلى عمل دائب، في حلقات متداخلة

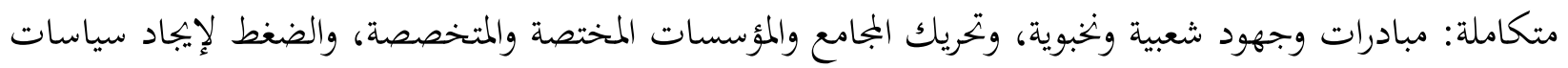
ومبادرات رسمية متجاوبة، وإشراك وسائل الإعلام وتفعيل دورها في القضية، ثم تستمر الدورة على هذا النحو. وفما يلي بعض الاقتراحات العملية التي يمكن إنجازها، كما يمكن تطويرها أو الزيادة عليها. 1. تأسيس جمعيات ولجان ومراكز لخدمة اللغة العربية والدفاع عنها والتصدي لمن يسيئون إليها وإلى مكانتها. 2. تأسيس جمعيات ومراكز ولجان لتعليم العربية لغير العرب، وخاصة المسلمين المقيمين في البلدان العربية.

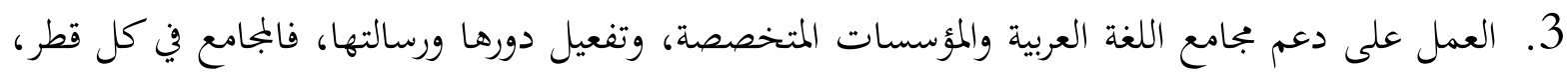

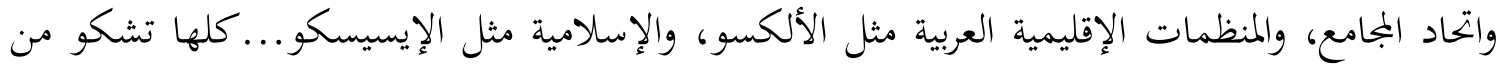
عدم قدرقا على تلبية الطموحات العزيزة المعلقة عليها.

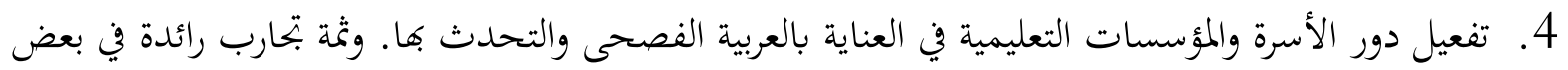

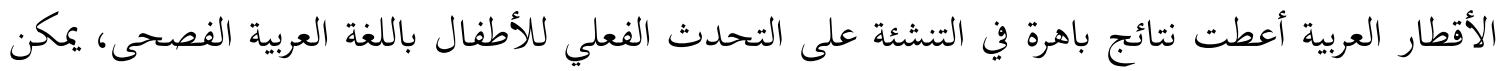
إبرازها وتبادل خبراتحا وتعميم فائدتها.

5. إنشاء مواقع إلكترونية متخصصة في موضوع اللغة العربية، وتخصيص حيز لهذا الموضوع في المواقع العامة،

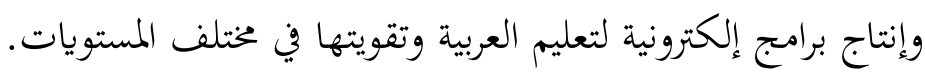
6. إحداث برامج تلفزيونية وإذاعية مخصصة لخدمة العربية. 7. إحداث جوائز قيمة لتشجيع الأفراد والمؤسسات على خدمة العربية والارتقاء .ها.

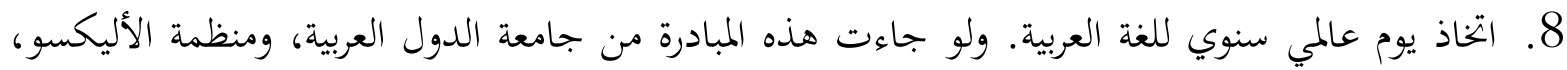

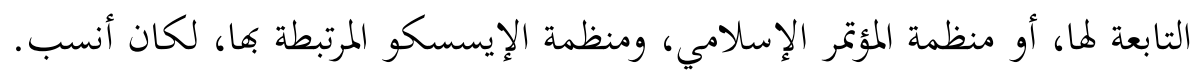

